\title{
ESTO QUE PASA Y SE QUEDA. PENSAMIENTO CHILENO ENTRE 1920 Y 1950
}

\author{
Mario Berríos C.*
}

En los años treinta había conciencia de crisis. Desde allí se le interroga sobre orígenes, causas, coluciones de lo ocurrido con posterioridad. Incluso para algunos de los estudiosos de este período Je la historia de Chile es considerado, especialmente la década del treinta, eje y clave de comprensión de mucho de lo ocurrido en los años recientes de nuestra historia nacional.

No cabe duda que todo el período fue un tiempo de mucha inseguridad: sin ir más lejos sólo in un año (desde el 4 de diciembre de 1931 al 24 de diciembre de 1932) hubo siete gobernantes Iiferentes. Para muchos de los actores del período ello era suficiente para hablar de una crisis. A os estudiosos del devenir nacional aquellos inicios contrastan con la relativa estabilidad que upuestamente ocurrió en los años subsiguientes.

Una de las primeras dificultades que es necesario superar consiste en la disímil valoración del :iempo que consideramos ya que no es precisamente la continuidad y la afirmación de un orden a establecido lo que prima. Más bien existe agitación política, reivindicativa. Tanto en el período nismo como en las visiones de los estudiosos posteriores, específicamente, los años treinta son istos como un escenario donde existen posibilidades de lograr lo que siempre se aspiró mientras fue para otros es el mundo entero el que se viene abajo.

La contradicción a la que hacemos referencia enmarca el espacio de tiempo entre dos hechos - ue hacen sonreír de satisfacción triunfadora a unos y deja a otros con la sensación de la derrota: in 1920 se dicta la ley de Instrucción Primaria Obligatoria después de una ardua lucha en el Parlamento como le consta al entonces director de Educación Darío Salas. Ahora se supone, a ?artir de esta ley, que todos, sin discriminación tendrán acceso al saber. La ilustración no es ?rivilegio de unos pocos, sino un bien de todos los ciudadanos. Se celebra una cierta mayoría de ¿dad. Al otro extremo cercano a mediados del siglo (1947) hay una ley que limita el derecho de I gunos. La Ley de Defensa de la Democracia bajo el gobierno de González Videla hizo sonreír a tros. Una ley de mayorías y otra de minorías nos convierten en parte de una modernidad que se .bre paso para todos y, al mismo tiempo, nos ubicamos en los bloques como resultado de la guerra ría.

Por otra parte ocurren en el período que estudiamos una serie de "logros" que se habían venido Iestando con anterioridad, de allí que se les considere punto de llegada: la mujer ejerce el derecho . voto (1935, en las elecciones municipales en 1949 es ampliado a toda la gama electoral).

En el sentido de llevar adelante el cumplimiento de promesas inacabadas el país asiste a la nauguración y difusión de los estatutos de los sindicatos, a la formación de partidos políticos lefinidos muy claramente desde el punto de vista ideológico, también participa en el conflicto :nundial a través de la radio. Todo ello y muchas otras acciones hacen que historiadores, socióogos, cientistas políticos vean y estudien con dedicación este período porque pareciera que en él e amalgama todo: utopía y fracaso, orden, estabilidad y caos. Se une la conciencia de unos que

* Versión de la ponencia presentada con el mismo título al Tercer Congreso de Culturas Hispánicas realizado en -antiago entre el 12 y 14 de agosto de 1992, organizado por el Departamento de Literatura de la Facultad de Filosofía y imanidades de la Universidad de Chile. 
despiertan y la inconciencia de otros que no quieren ver lo que ocurre. En fin. Se abrieron nuevos caminos, se cierran otras certezas, los temas de Chile vuelven al tapete y todos tienen opinión.

En el mismo periodo Gabriela Mistral obtiene el Premio Nobel y la Iglesia su primer Cardenal.

Hablar de "entre 1920 y 1950 ", casi treinta años de historia nacional es una división arbitraria. Ella responde, más bien, a una cierta necesidad de exposición de la historia reciente. Nosotros asumimos que de esa división los contemporáneos no tuvieron una conciencia plena. Pero, en los últimos años la pregunta por nosotros mismos nos ha llevado a interrogarnos por el origen. La verdad es que nos preguntamos desde fuera del mismo período que consideramos. Así hemos buscado en dicha gestión lo medular de lo que consideramos es la crisis de Chile. En nuestras preocupaciones "a posteriori" hemos relevado hechos de este período entre ellos la formulación de una nueva constitución política que se abrió paso dificultosamente desde su nacimiento y que después fue vista como la máxima expresión de la democracia estable; por lo mismo hemos estudiado los partidos políticos, los movimientos sociales y populares, en fin, todo aquello que parecía dar vida a lo nuestro y que nos distingue como país. En consecuencia, el estudio del pensamiento del período puede darse al menos desde dos puntos de vista diferentes:

uno. Desde la interrogación necesariamente ubicada en las respuestas exigidas en un momento como el actual donde es imperioso encontrạr los caminos de reconstrucción de la democracia, donde buscando causas y consecuencias, intentamos reponer los temas que nos mueven profundamente.

dos. Desde el período mismo, preguntando a sus actores, a sus diarios, a sus avisos económicos, poniéndonos la exigencia de pensar como esos años para que, comprendiendo desde dentro, podamos extraer el conocimiento que el período aporta.

Ambas posibilidades de estudio del pensamiento de un período son legítimas. Perfectamente podemos articular las preocupaciones presentes recurriendo a ciertos hechos o temas del pasado. Así hablamos de aquello que nos interesa desde nuestra perspectiva presente.

Es igualmente legítimo ver, como exigencia, en el estudio del pensamiento de un período rehacer la historia, los modos de pensar con el objeto que, desde ellos mismo, podamos decir con toda propiedad "este es el pensamiento del período". En ambos casos no se obvia la recurrencia a fuentes documentales.

Una y otra propuesta aparecen como legítimas y posibles, pero sólo son parte del método. Lo que en realidad interesa poner en la discusión, en primer lugar, es lo que hemos pensado, cuales han sido nuestros sino teóricos, como es que frente a situaciones concretas que hemos debido enfrentar constituimos espacios teóricos que se transforman en claves hermenéuticas de nosotros mismos. La descripción de los hechos, la consignación de las propuestas teóricas, la indagación en las diversas fuentes las cuales, a su vez, reflejan los diversos problemas exigen establecer una relación entre lo que ocurre, las manifestaciones en las que plasma aquello y se transforma en clave interpretativa. Así podemos decir que los conceptos se crean, se acuñan de diversa mane- ra. Al considerar un período, en el caso nuestro, 1920-1950 no sólo es necesario describir lo que ocurre, la pregunta es más bien sobre los términos, conceptos, imágenes que se amalgamaron y continuaron estando presentes en nuestro devenir legando a formar parte de lo que somos.

Los años treinta han sido considerados como los claves en una historia chilena moderna, varios autores o grupos de ellos vuelven sus ojos a dicho período porque allí intuyen la gestación de certezas.

La pregunta es entonces por los conceptos y no por el devenir concreto, empírico. Esto último sólo nos conduce a la mirada nostálgica de lo que fue. Más bien hay que preguntarse por los conceptos que se acuñan en un tiempo determinado, sobre las concepciones que afianzan su 
espacio y se reproducen posteriormente. Qué aspectos de nosotros mismos nacieron en este momento y se incrustaron en la vida nuestra, formando parte de nuestras convicciones, de nuestras formas hermenéutica de conocer la realidad. En una palabra, como es que llegamos a pensar como hoy pensamos cuando discutimos sobre nosotros mismos.

En consecuencia, hablar del pensamiento chileno es plantearse no sólo el contenido del discurso que hemos pronunciado. Es también, y en mi visión, ante todo, explicitar las columnas que lo sostienen: nuestra paternidad y maternidad al mismo tiempo.

Hacer historia del pensamiento es asistir al origen de nosotros mismos, de nuestras propias categorías.

En lo que sigue (tres puntos) se intentará mostrar algunos de estos conceptos que hasta el día de hoy hemos heredado. Intentanos revelar algunos pensamientos claves para desvelar algunas categorías que han estado a la base de nuestra vida nacional.

\section{AQUELLO DE LA CRISIS}

Al considerar el período hay un tema que salta a la vista y es que existe una conciencia generalizada que existe una crisis en el país.

Alone se refiere a ello en un texto publicado en 1945 de esta manera: "y después vienen en prosa profesores de liceo o de Universidad, jóvenes provincianos desconocidos, nombres que runca se habían escuchado antes, algunos de tan humilde extracción como peones, gañanes, lustrabotas y hasta vendedores de diarios. Es un trastorno completo que da la sensación no sólo de otra época, sino de otro país y hasta de otra raza"l.

A este punto de vista se suman otros y todos coinciden en la conciencia de la crisis. La inseguridad política aporta la vertiente mayor que alimenta la conciencia de crisis. Los chilenos in el mismo instante que toman conciencia se ven en la obligación de dar cuenta de ello: la crisis pasa a ser contenido del pensamiento.

Pero no sólo se describe y se tiene lucidez que un mundo se viene abajo (y que quién sabe lo que vendrá) es necesario también buscar responsables. Vicente Huidobro (por ejemplo) en el Balance Patriótico caracteriza esas crisis como la falta de hombres y, aun cuando escribe en 1924 , 1 tener delante a un presidente que renuncia, en realidad de que está hablando es de una clase iocial que ya no es capaz de seguir asumiendo el papel organizador de la sociedad: "un país que ipenas a los cien años de vida está viejo y carcomido lleno de tumores y de superacciones de ¿áncer como un pueblo hubiera vivido dos mil años y se hubiera desangrado en heroísmo y zonquistas. Todos los inconvenientes de un pasado glorioso pero sin la gloria. No hay derecho nara llegar a la decadencia sin haber tenido apogeo"2.

Esta denuncia es recogida en el texto de Leopoldo Arce "La crisis chilena" (1932) como un roblema que afecta todo el país, aún los grupos emergentes.

A estas constataciones se sumaron otras. Por ejemplo "en el momento actual el carro del Estado ha saltado de sus rieles en que caminaba y marcha por un camino que no es el normal"3. Al lado de ello se vive en otros sectores el pavor de las constataciones "Chile no es asî" :firiéndose a la obra "La viuda del conventillo" de Alberto Romero recomendándose al mismo iempo que es una novela que no debe ser leída ${ }^{4}$.

\footnotetext{
${ }^{1}$ Hernán Díaz Arrieta, Reseña de la historia cultural de Chile. Buenos Aires, 1945, p. XxvI.

${ }^{2}$ Vicente Huidobro, Balance Patriótico. En: Mario Góngora, Ensayo histórico sobre la noción de Estado en Chile en s siglos XIX y XX. Santiago. 1981, pp. 113-120.

${ }^{3}$ Revista Masónica de Chile. № 10. 1924, p. 322.

${ }^{4}$ La Revista Católica, 17 de enero de 1931.
} 
La iglesia vive cl remezón de la separación con el Estado y ve que se abre un nuevo camino que más tarde la Falange Nacional hará práctico: es posible ser católico y no ser voto conservador.

Todo este trajín trajo como consecuencia la reivindicación de la política como espacio para resolver los problemas nacionales en la cual podían participar muchos más que antes. La política se transforma en un verdadero espacio público, diversos sectores encuentran su orgánica para participar en la política que es el camino para acceder el control del Estado. El punto de mira cambia.

No es sólo un resultado de la conciencia tematizada de la crisis la reivindicación de la política. Llegó de la mano la obligación de pensar lo coyuntural y de tener opinión frente a lo que ocurre. Lo nuevo es que todos podían decir algo reconociéndose cada uno con el espacio propio para explicarse delante de los demás.

La crisis no era un elemento que se viviera solo en el país. Los informes internacionales de Zig Zag que alimentaban a un grupo importante de personajes chilenos sobre los acontecimientos de Europa eran leídos con el prisma de la experiencia nacional.

La crisis puso de manifiesto un gran temor escondido de la sociedad chilena: había que aceptar que se pensara distinto. Hubo, es cierto, una aceptación a regañadientes de los otros.

También mostró la situación vivida en el país lo débil que era la consistencia de lo chileno. En este sentido Domingo Melfi al escribir en 1931 "un país tan constitucionalista como éste asistió luego, impasible a la destrucción de todas las disciplinas constitucionales. El derecho y la ley fucron vilmente atropellados y nadie dijo 'Esta boca es mía' ". Y agrega refiriéndose siempre al período de la presidencia de Ibáñez "Casi todos los políticos olvidaron a los creadores de la República y se apresuraron a acercarse a la mesa del festín que presidía el dictador y sus ministros. Los pocos ingenuos que se dieron a la manía de protestar fueron rápidamente silenciados" ${ }^{\prime 5}$, así Melfi les da razón a todos los que constatan la crisis.

Efectivamente. La crisis es respecto a la idea de Chile que se tenía, es relativa a los nuevos elementos que ahora será necesario considerar, es la perplejidad ante lo que de pronto se rehace.

\section{LO CHILENO}

Interesa hacer notar un segundo aspecto, unido al anterior, pero que apunta más al contenido. Se trata de la pregunta sobre lo chileno.

En buena medida Hernán Godoy con sus estudios y con la recopilación de textos no ha hecho sino recoger esta pregunta cuyo origen ubicamos para el pensamiento chileno contemporáneo en los autores de los "Ireinta". No afirmamos que aquí se haya iniciado la discusión sobre el tema, simplemente que nuestra idea actual es deudora de lo que en este período se ciment ${ }^{6}$.

La discusión sobre lo chileno versó sobre cuales son las características, las negaciones. También sobre las modas y modelos extranjeros, que no tomábamos suficientemente lo nuestro y que, cuando lo hacíamos, terminábamos refiriéndonos a elementos pintorescos que se preocupan de exaltar exactamente lo que nos impide realizarnos. La discusión en cuestión terminó asimilando todo al problema de la identidad: que es lo que nos hace ser nosotros mismos.

En realidad el problema tiene una doble dimensión. Por una parte, siguiendo a Tomás Moulián "entre 1938-1947 se caracteriza una gradual intensificación de la democratización política en consonancia con el ritmo de la industrialización"? A vanzar hacia un período en el cual

\footnotetext{
${ }^{5}$ Domingo Melfi, Dictadura y Mansedumbre. Santiago 1931, p. 7.

${ }^{6}$ Hernán Godoy, El carácter chileno, Santiago 1976.

${ }^{7}$ Tomás Moulián, Discusión entre Honorables, p. 107.
} 
por medio de la industrialización del país, de la creación de la Corfo, de la sustitución de importaciones, en fin, de todo ello fluía la idea que estábamos en el camino de la realización de la utopía del progreso. Allí residía la realización de lo chileno. Ese era el contenido de la plenitud modernizadora.

Pero, por otra parte, ello significaba la participación de las grandes mayorías populares organizadas que con su creación de sindicatos, centrales sindicales y partidos políticos obligaba a la sociedad en su conjunto a considerarla provocando incluso que la Universidad se volcara hacia el todo social por medio del concepto de extensión universitaria. Había aires de refundación (no sin razón la Universidad recomenzó la publicación de las obras de Bello).

Pero también la chilenidad podía ser un freno al progreso en la medida que la costumbre de que en el camino se arregla la carga al decir de Enrique Molina ${ }^{8}$ debía ser desterrado, como también podía significar la señal de adquisición de una conciencia propia como lo constatamos en Finnlayson" o en la Mistral "cl pueblo se adueñado del aire" 10 .

En síntesis la "discusión sobre la discusión" en tomo a la chilenidad tenía que ver con los cambios modernizadores operados en el país. La reorientación de la idea de lo chileno por una parte y la conciencia de ser sujeto se encuentran.

Justamente en este punto es donde se reformula la idea de pueblo. Esta se acuña, se estructura, dando pie a que todos los actores desde diversos bandos, desde diversos puntos de vista acuerdan que la idea de pucblo debe estar en relación con la modernidad ya sea como parte de la adaptación para ser productivo, ya como conciencia de ser protagonisla. Ambas formas se encuentran y Jesencuentran en la fundación de partidos en cl período, en la construcción de puentes, embalses, ¿dificios, escuelas y puertos.

A chile se le siente como propio desde todos los sectores y así acrisola la idea que la crisis xiste porque se está cediendo paso a una nueva modernidad. Ahora se empieza a realizar masivamente en la mente de muchos y de los más importantes, la utopía del progreso. Ahora sí enemos razón para vivir y soñar. No es posible excluir a nadie, dicen unos, todos somos la gran amilia de Chile, dicen otros. Ahora formamos parte de la universalidad dicen todos, porque Chile s moderno.

\section{LA CIMA}

Zontribuyó al afiatamiento de este contenido (Chile-Modernidad) algunos aspectos externos. La lea de raza había entrado fuertemente en la vida nacional por medio de la preocupación por la ilud, por los tipos humanos. En las preocupaciones que los magacines de la época otorgan mportancia está lo exótico, como es la vida en otros lugares, el valor de lo estético. La sensación ¿ universalidad se une a la utilización de nuevas técnicas: la radio, el disco, el cine.

De nuevo nos encontramos en un doble estándar.

Por una parte hay conciencia de la modernidad y por otra conciencia de la propia capacidad. o se es pura copia de lo externo, antes bien se es consciente de ello precisamente por la valoración lo propio. La traducción pasa a ser una forma de apropiación.

Las exigencias planteadas en el plano económico por la sustitución de importaciones, la Lesidad de establecer un camino constitucional donde el caudillo es reemplazado por la ley nvirtiéndose ésta a su vez en un caudillo ordenador de la sociedad.

\footnotetext{
${ }^{8}$ Enrique Molina, Los defectos de nuestro carácter. Atenea № 103, marzo 1936.

${ }^{9}$ Clarence Finulayson, Teoría del pueblo clileno. Acción Social, № 76. 1939.

${ }^{10}$ Gabriela Mistral, La música americana de los Cuatro Huasos. En: Recados Contando a Chile. Santiago 1957. 217.
} 
Se legitima la conciencia que es tarea de todos contribuir al éxito de esta empresa, aunque ello signifique reformularnos. Esta necesidad de espejo de la realidad que nos pone el criollismo, los ensayistas, las organizaciones sociales, no es la confrontación bipolar, como ha sido la mayoría de las veces entendido, es la construcción de lo moderno.

La afirmación del grupo social "clase media" que tiene una misión en la estabilidad del país. Una clase obrera cada vez más organizada. La idea de una base telúrica en nuestro ser. Nada de todo esto oscurece la discusión de la conyuntura en el período así en los temas de la crisis, la chilenidad, lo moderno, lo popular es posible encontrar al menos dos tendencias. Por una parte, se recurre al pueblo desde una visión apologética expresada en el lamento por lo que no es, o en la defensa de estados de derecho como modelos a cumplir, o en la defensa de tradiciones a las cuales se les quiere dar el carácter de universalidad. Por otra parte, también se recurre en el período a una visión refundadora del país en las nuevas condiciones, en las cuales la idea de modernidad, de la conciencia de ser sujeto, de haber encontrado los caminos de despliegue y de reformulación, aparentemente definitivos para Chile.

\section{EN SÍNTESIS}

Durante el período que presentamos asistimos al nacimiento dificultoso de reformulaciones. Son muchas las cosas nuevas y todos deben aportar algo más en esa novedad. La Universidad asume el papel de formar parte de este camino de modernidad: formar profesionales y extender sus conocimientos. Las leyes laborales y el Código del Trabajo es como construir una sólida defensa.

Existe conciencia que, queramos o no, estamos incluidos en la universalidad. Hay que responder a las exigencias de quienes nos exportaron bienes de capital. Al obrero se le ha exigido "profesionalismo". Si es chileno es bueno no fue sólo una frase, sino un programa de vida.

La chilenidad permea la organización política de algunos partidos y a través de ella exigimos nuestra parte en la universalidad. Es una forma distinta de reformular el país. En fin se estructuró la imagen de nosotros mismos: crisis vivida y superada, lo chileno triunfante con los bienes de consumo en la casa y la industria en la periferia, el pueblo organizado y protagonista.

Cuando en los noventa, medio siglo más tarde, nos preguntamos por la historia de ese período reconocemos en ella parte de lo nuestro como también aquello que dejó de serlo.

¿Es posible reconstruir el pensamiento de un período sin referencia al presente que nos inunda?

Hoy día no releemos los autores ni los hechos. Sólo pretendemos dar cuenta de la memoria que ellos nos legaron con cuyas categorías seguimos leyendo lo nuestro. Aparece como indispensable reconocerlas y una vez leídas será posible encontrar los ejes de nuestro pensamiento más allá de las coyunturas, los modelos y las construcciones.

Es como un cierto hábito que forma parte de nosotros, que pareciera que no está, pero que su ausencia nos ahoga y nos desespera. Es el aire que es contenido, es el verdadero espacio. Con razón aquel periódico sueco que comentó el premio nobel de Gabriela Mistral en 1945 señalo que quićn ha escrito así sobre el aire:

Esto que pasa y se queda, esto es el Aire, esto es el Aire, que, sin boca que tú lo veas, te toma y te besa, padre amante. Ay, le rompemos sin romperle; herido vuela sin quejarse, 


\section{ESTO QUE PASA Y SE QUEDA}

y parece que a todos lleva

y a todos deja, por bueno, el Aire...

quien haya escrito esto no sólo merece el premio, sino que ha vivido mucho. Entre 1920 y 1950 parece que pasó mucho, pero se quedó con nosotros mucho más.

Santiago, agosto de 1992 